\title{
STUDIES OF BINDING $\mathrm{C}_{3}$-SUBSTITUTE RIFAMYCINS TO HUMAN AND BOVINE SERUM ALBUMIN
}

\author{
Alessandro Assandri, Antonio Perazzi and Marisa Berti \\ Gruppo Lepetit S.p.A., Via Durando, 38, Milan, Italy \\ (Received for publication March 15, 1977)
}

\begin{abstract}
The interactions of a series of $\mathrm{C}_{3}$-substituted rifamycins with human and bovine serum albumins were studied in order to find possible correlations between the degree of binding and the structural features of the various molecules.

The results obtained indicate some of the physicochemical properties and, therefore, of the structural requirements which appear to determine or influence the bonding mechanisms of this series of rifamycins. Two types of interaction were found to exist, ionic and hydrophobic types. The findings suggest that the inhibition by protein of the antibacterial activities of these antibiotics depends on the type of bonding mechanism rather than the degree of binding.
\end{abstract}

The importance of reversible binding to serum proteins, and in particular to the albumin fraction, in determining the body distribution of a drug has been repeatedly demonstrated ${ }^{1,2}$. Moreover, the influence of protein-binding on the effectiveness of antibiotics against infections in vivo has been assessed $^{3,4)}$.

Our interest in $\mathrm{C}_{3}$-substituted rifamycins, a class of antibiotics with a broad antibacterial spectrum ${ }^{51}$, led us to investigate in vitro the characteristics of the reversible binding of a series of these drugs to human and bovine albumin. A correlation has been found between the binding strength and the molecular structure, a result which promises a useful approach in predicting the physiological disposition of new semi-synthetic rifamycins.

\section{Materials and Methods}

1. Chemicals

$37-{ }^{3} \mathrm{H}-\mathrm{SV}$, (rifamycin SV), spec. act. $0.408 \mathrm{mCi} / \mathrm{mmole}$; $37-{ }^{3} \mathrm{H}-4-\mathrm{DSV}$ (4-deoxy-rifamycin-SV), spec. act. $0.471 \mathrm{mCi} / \mathrm{mmole}$ (rifamycins SV and DSV were obtained biosynthetically with ${ }^{3} \mathrm{H}-\mathrm{methio-}$ nine); $38-{ }^{14} \mathrm{C}-\mathrm{AF} / \mathrm{AP}$ (3-(1-piperazinyl)imino methyl rifamycin $\left.\mathrm{SV}\right)$, spec. act. $1.62 \mathrm{mCi} / \mathrm{mmole}$; $38-{ }^{14} \mathrm{C}$ AF/AMP, (3-[[(4-methyl-1-piperazinyl)imino]methyl]rifamycin SV), spec. act. $10.77 \mathrm{mCi} / \mathrm{mmole}$; 38 ${ }^{14} \mathrm{C}$-AF/AETP, (3-[[(4-ethyl-1-piperazinyl)imino]methyl]rifamycin SV), spec. act. $10.29 \mathrm{mCi} / \mathrm{mmole}$; $38-{ }^{14} \mathrm{C}-\mathrm{AF} / \mathrm{ACPP}$, (3-[[(4-cyclopentyl-1-piperazinyl)imino]methyl]rifamycin SV), spec. act. $10.21 \mathrm{mCi} /$ mmole; $38-{ }^{14} \mathrm{C}-\mathrm{AF} / \mathrm{ABDP},(3-[[(4-\mathrm{cis}-\mathrm{aminobenzyl}-1-2,6$-dimethyl-piperazinyl)imino]methyl]rifamycin $\mathrm{SV}$ ), spec. act. $12.15 \mathrm{mCi} / \mathrm{mmole} ; 38-{ }^{14} \mathrm{C}-\mathrm{AF} / \mathrm{API}$, (3-[[1-piperidinyl)imino]methyl]rifamycin SV), spec. act. $1.79 \mathrm{mCi} / \mathrm{mmole}$. The molecules were synthesized in their hydroquinonic forms (HQ) by G. SARTORI of Gruppo Lepetit, Milan. The quinonic forms (Q) from the same compounds were prepared by the authors by oxidation with $\mathrm{MnO}_{2}$ in $\mathrm{CHCl}_{3}$. For formulas see Fig. 1.

Human serum albumin (HSA), bovine serum albumin (BSA) were purchased from Sigma Chem. Co. All calculations are reported in terms of a molecular weight (Mw) of 69,000 for HSA and 67,000 for BSA.

2. Binding assay

Because of the high lipophilicity of many of the rifamycins under investigation, the binding could not be determined by those traditional methods utilizing membranes, e.g., equilibrium dialysis. In- 
Fig. 1. Rifamycins studied, basic structure and type of substitutions
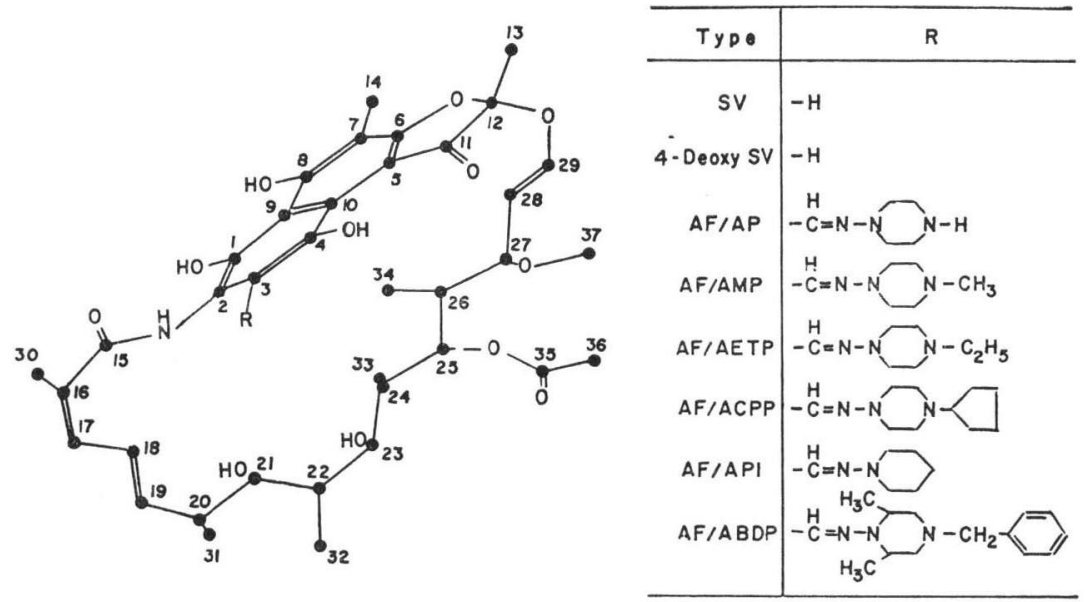

stead, a gel filtration technique, the "large zone-small zone elution method", was used": Sephadex G-25 (medium type, from Pharmacia Fine Chem.) swollen in $0.05 \mathrm{M}$ sodium phosphate buffer, at the stated $\mathrm{pH}$ values, with or without $10^{-3} \mathrm{M}$ ascorbic acid was packed in an LKB glass column $(0.9 \times 30 \mathrm{~cm}$, with thermostatic jacket). Once the partition coefficients of the different rifamycins had been determined, in the absence of the macromolecular component, the columns were pre-equilibrated with the buffered protein solutions, and loaded with the ligands $(10 \mu \mathrm{g})$ dissolved in $0.3 \mathrm{ml}$ of the same medium containing $0.025 \mathrm{ml}$ of ethanol. Elution was performed with the same buffer solutions, at $4^{\circ}$ and $37^{\circ} \mathrm{C}$, and $0.5-\mathrm{ml}$ fractions were collected.

The "large zone-small zone elution method" permits calculation of the Bound/Free ratio (B/F) of the small molecular weight ligands by means of the following equation:

$$
\frac{{ }^{0} V_{e}-V_{o}}{V_{e}-V_{o}}-1=\frac{{ }^{0} \sigma}{\sigma}-1=\frac{B}{F} K_{a} \times n\left(P_{t}-P_{b}\right)
$$

where $V_{e}$ and ${ }^{0} V_{e}$ are the elution volumes of the small $\mathrm{Mw}$ ligands in the presence or the absence of the macromolecules; $\sigma$ and ${ }^{0} \sigma$ are the corresponding chromatographic partition coefficients; $V_{o}$ is the void volume of the column. $B$ and $F$ refer to the bound and free fractions of small Mw ligands, $K_{a}$ is the association constant, and $n$ is the number of identical, non-interacting, binding sites of the macromolecule. $\quad P_{t}$ and $P_{b}$ are the total and bound protein concentrations.

From equation (1) once the $B / F$ ratio has been calculated and $P_{t}$ known, and when $P_{t} \gg B$, the procuct $K_{a} \times n$, defined as the "combining affinity" is given by:

$$
K_{a} \times n=\frac{B}{F \times P_{t}}\left(\text { liters mole }{ }^{-1}\right)
$$

Since in our binding assays the assumption above $\left(P_{t} \gg B\right)$ met the experimental conditions it was convenient to use the "combining affinity" as the reference parameter of the binding strength.

3. Thermodynamic parameters

$\Delta G^{0}, \Delta H^{0}$ were calculated from the following equations:

$$
\begin{array}{ll}
\Delta G^{0}=R T \ln K_{a} \times n & (\mathrm{cal} / \mathrm{mole} \text { ligand bound }) \\
\Delta H^{0}=\frac{\ln \left(K_{a_{1}} \times n_{1} / K_{a_{2}} \times n_{2}\right)}{\left(1 / T_{2}-1 / T_{1}\right)} & (\mathrm{cal} / \mathrm{mole} \text { ligand bound }) \\
\Delta S^{0}=\frac{\Delta H-\Delta G}{T} & \left(\mathrm{cal} \cdot \mathrm{mole}^{-1} \text { degree }^{-1}\right)
\end{array}
$$

4. Determination of minimal inhibitory concentration (MIC)

MIC's were determined by the serial dilution technique published by ARIOLI et al. ${ }^{71}$ in the presence 
or absence of $30 \%$ bovine serum corresponding to a final concentration of $12 \%$ BSA. The test strain was Staphylococcus aureus ATCC 6538.

5. Lipophilic indices

$R_{m}$ were determined by reversed-phase thin-layer chromatography by PeLIzZA et al ${ }^{81}$, according to the formulation of BOYCE and MiLBorRow ${ }^{9}$ :

$$
R_{m}=\log \left(\frac{1}{R_{f}}-1\right)
$$

6. Ionization constants

$\left(\mathrm{pKa}_{1}\right.$ and $\left.\mathrm{pKa}_{2}\right)$ of the different rifamycins were determined by spectrophotometric analysis, by Radaelli et al. and Pasqualucci et al. ${ }^{10,11,12)}$.

\section{Results}

\section{Preliminary}

In a previous work ${ }^{6)}$ the authors demonstrated the binding of HQ-AF/AMP (rifampicin) to the albumin fraction of bovine serum. Since rifamycins can exist in two forms, i.e., quinones and hydroquinones, which might have different affinities for the different serum fractions, the investigation was then repeated with oxidized rifampicin, with the same results. Because of this and because the albumin fraction is present in the largest relative amount in plasma, albumin is pharmacokinetically the most important component. Therefore, we have limited our investigations to the albumin fractions from human and bovine serum proteins. This does not exclude the possibility that among the different rifamycins studied some of them might bind to protein fractions other than albumin.

\section{Binding of HQ and Q-Rifamycins to HSA and BSA}

The "combining affinities" of the complexes between the rifamycins SV, AF/AP, AF/AMP, AF/

Fig. 2. Interactions between $\mathrm{HQ}$ rifamycins and BSA or HSA: graphical estimation of the combining affinities ( $K_{a} \times n$ products).

On the ordinate are the Bound/Free ratios, on the abscissa the albumin concentrations.

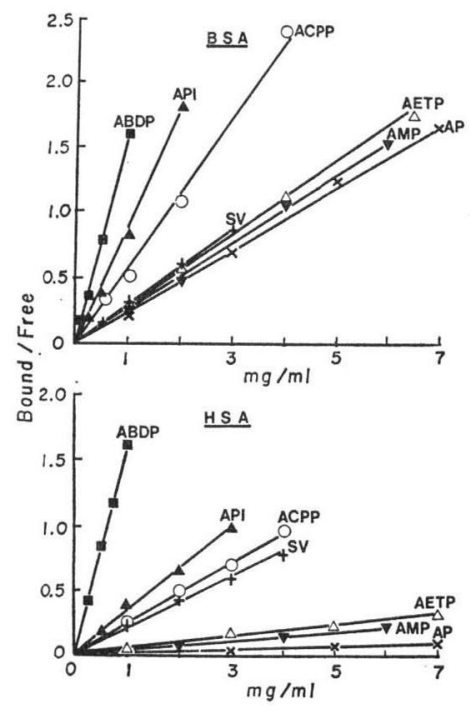

AETP, AF/ACPP, AF/ABDP, AF/API and HSA or BSA were measured by the "large zone-small zone elution method" at $37^{\circ} \mathrm{C}$ and $\mathrm{pH} 7.4$ in phosphate buffer in presence (hydroquinones) or

Fig. 3. Interactions between $\mathrm{Q}$ rifamycins and BSA or HSA; graphical estimation of the combining affinities ( $K_{a} \times n$ products).

On the ordinate are the Bound/Free ratios, on the abscissa the albumin concentrations.

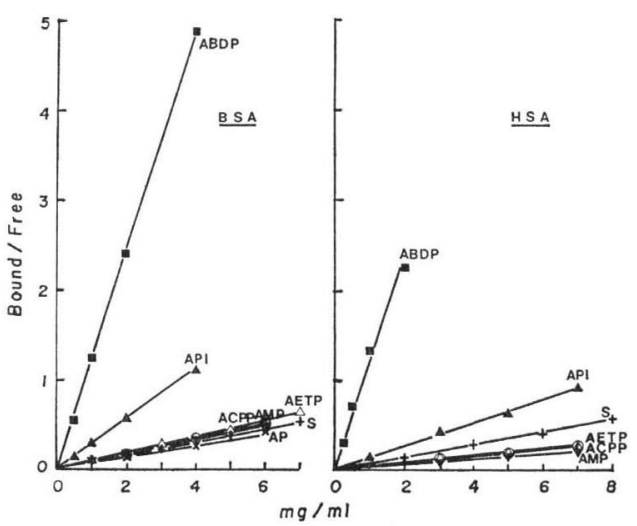


Table 1. Combining affinities-values of $\mathrm{Q}$ and $\mathrm{HQ}$ rifamycins to bovine and human serum albumin $37^{\circ} \mathrm{C}, \mathrm{pH} 7.4$

\begin{tabular}{l|r|r|rr}
\hline \multirow{2}{*}{ Type } & \multicolumn{3}{|c}{$K_{a} \times n \times 10^{-4} \pm$ S.E. (liters mole ${ }^{-1}$ ) } \\
\cline { 2 - 5 } & \multicolumn{2}{|c|}{ BSA } & HSA \\
\cline { 2 - 5 } & HQ & Q & HQ & Q \\
\hline 4-DSV & $2.76 \pm 0.11$ & - & $1.46 \pm 0.06$ & $0.51 \pm 0.01$ \\
SV & $2.05 \pm 0.08$ & $0.56 \pm 0.02$ & $0.11 \pm 0.02$ & n.d.* \\
AF/AP & $1.60 \pm 0.05$ & $0.49 \pm 0.08$ & $0.28 \pm 0.02$ & $0.21 \pm 0.04$ \\
AF/AMP & $1.75 \pm 0.06$ & $0.61 \pm 0.03$ & $0.36 \pm 0.03$ & $0.28 \pm 0.02$ \\
AF/AETP & $2.01 \pm 0.04$ & $0.63 \pm 0.09$ & $1.71 \pm 0.04$ & $0.27 \pm 0.04$ \\
AF/ACPP & $3.59 \pm 0.10$ & $0.54 \pm 0.05$ & $8.73 \pm 0.42$ \\
AF/ABDP & $10.31 \pm 0.37$ & $8.31 \pm 0.13$ & $11.35 \pm 0.24$ & 8.73 \\
AF/API & $5.52 \pm 0.27$ & $1.99 \pm 0.03$ & $2.50 \pm 0.14$ & $0.95 \pm 0.05$ \\
\hline
\end{tabular}

* n.d.: non detectable.

in absence (quinones) of ascorbic acid. The results, as reported in Figs. 2 and 3 where the calculated $B / F$ ratio is plotted against the protein concentration, show for the series of ligands considered that affinity values range between $10^{3}$ and $10^{5}$ (see Table 1). Higher binding strengths were found for BSA, as compared with HSA, and it is very apparent that the affinity values are much lower for the Q-forms. There is however, an exception to the general behaviour: rifamycin AF/ABDP seems to bind with about the same strength to both BSA and HSA, in either its Q or HQ form.

\section{Approaches to the Bonding Mechanism}

In order to clarify some of the structural features affecting the interactions between these rifamycins and bovine albumin the following experiments were carried out.

\section{(1) Binding of 4-deoxy-rifamycin SV to BSA}

The large difference in binding strength between $\mathrm{Q}$ and $\mathrm{HQ}$ rifamycins suggested that the hydroxyl groups at $\mathrm{C}_{1}$ and/or $\mathrm{C}_{4}$ are involved in the bonding mechanism, and it was of interest to verify whether and to what extent 4-DSV would bind to BSA. Actually, the "combining affinity" measured for 4-DSV proved to be even higher than that for SV (see Table 1), indicating that only the $\mathrm{C}_{1}$-hydroxy group is relevant to the bonding reaction.

(2) Temperature dependence

In evaluating the forces involved in the binding of a ligand by protein, it is often useful to determine whether the free energy change comes about from a change in the heat content $(\Delta \mathrm{H})$ or in the entropy of the system $(\Delta S)$. In effect, no variation of the binding affinities could be observed for the rifamycins studied within the range of temperature between $4^{\circ}$ and $37^{\circ} \mathrm{C}$, with the sole exception of SV for which the enthalpy change accounts for about one third of the total free energy change (Table 2).

(3) $\mathrm{pH}$ dependence

All the investigated molecules possess, in their hydroquinonic form, an acid function $\left(C_{1}-C_{8}\right.$ dihydroxy), however, while rifamycin SV has no other ionizing groups, all the others have one basic nitrogen function.

Moreover the $\mathrm{pK}_{\mathrm{a}_{1}}$-values of the rifamycins studied are with the sole exception of AF/API, comparable to that of $\mathrm{SV}\left(\mathrm{pK}_{\mathrm{a}_{1}}=1.8\right)$. For $\mathrm{AF} / \mathrm{API}\left(\mathrm{pK}_{\mathrm{a}_{1}}=4.8\right)$, the presence of a hydrazonic group causes a weakening of the $\mathrm{C}_{1}-\mathrm{C}_{8}$ dihydroxy acid function; this effect is, on the contrary, neutralized in 
Table 2. Thermodynamic parameters of the interactions between HQ-rifamycins and BSA. The lipophilic indices of the ligands are also reported.

\begin{tabular}{l|c|c|r|r}
\hline \multicolumn{1}{c|}{ Type } & $\Delta G^{0}$ & $\Delta H^{0}$ & \multicolumn{1}{c|}{$\Delta S^{0}$} & $R m^{*}$ \\
\hline SV & -6114 & -2077 & +13.02 & -0.930 \\
AF/AP & -5964 & 0.0 & +19.24 & -0.293 \\
AF/AMP & -6018 & 0.0 & +19.41 & -0.277 \\
AF/AETP & -6103 & 0.0 & +19.69 & -0.244 \\
AF/ACPP & -6461 & 0.0 & +20.84 & -0.138 \\
AF/ABDP & -7111 & 0.0 & +22.94 & +0.340 \\
AP/API & -6726 & 0.0 & +21.70 & -0.086 \\
\hline
\end{tabular}

* Data from Pelizza et al. ${ }^{81}$.

Table 3. $\mathrm{pH}$ Dependence of the interaction between HQ-rifamycins and BSA

\begin{tabular}{l|c|c|c|c}
\hline \multirow{2}{*}{ Type } & \multirow{2}{*}{$p K_{a_{1}}$} & $p K_{a_{2}}$ & \multicolumn{2}{|c}{$K_{a} \times n \times 10^{-4} \pm$ S.E. } \\
\cline { 3 - 5 } & & & $\mathrm{pH} 5.8$ & $\mathrm{pH} 7.4$ \\
\hline SV & 1.8 & - & $7.96 \pm 0.28$ & $2.05 \pm 0.08$ \\
AF/AP & 1.9 & 8.2 & $0.85 \pm 0.10$ & $1.60 \pm 0.05$ \\
AF/AMP & 1.7 & 6.7 & $1.02 \pm 0.13$ & $1.75 \pm 0.06$ \\
AF/AETP & 1.7 & 6.7 & $1.25 \pm 0.12$ & $2.01 \pm 0.04$ \\
AF/ACPP & 2.4 & 6.5 & $1.52 \pm 0.05$ & $3.59 \pm 0.10$ \\
AF/ABDP & 2.6 & 6.0 & $3.90 \pm 0.16$ & $10.31 \pm 0.37$ \\
AF/API & 4.8 & - & $6.56 \pm 0.23^{*}$ & $5.52 \pm 0.27$ \\
\hline
\end{tabular}

$p K_{a_{1}}$ refer to the $\mathrm{C}_{1}-\mathrm{C}_{8}$ dihydroxy group (estimated in water), $p K_{a_{2}}$ refer to the $\mathrm{N}_{4}$ of the piperazine moiety (estimated in $80 \%$ of methylcellosolve).

* The AF/API pH-dependence was measured at $\mathrm{pH} 8.5$ instead of 5.8 because it was strongly retained by the gel matrix at the lower $\mathrm{pH}$-value.

the piperazine derivatives by the presence of the electrophilic aminic group $\left(\mathrm{N}_{4}\right)$ giving the internal salt ${ }^{8,13)}$.

The binding affinity of the complex SV-BSA rises with lowering of the $\mathrm{pH}$ (from 7.4 to 5.8) while the opposite occurs for all the other rifamycins (Table 3). The pH-dependence of the binding between AF/API and BSA could not be verified at $\mathrm{pH} 5.8$ because of its physico-chemical properties, the investigation was instead carried out at $\mathrm{pH} 8.5$.

(4) Binding strength and biological activity

It is known that the antibiotic effectiveness may be affected by the interaction with serum protein and that it is sometimes correlated with the concentration of the unbound fraction only ${ }^{31}$.

For this reason, we compared the antibacterial activities of the rifamycins in the presence and absence of $30 \%$ bovine serum ( $\simeq 12 \%$ BSA). The data, reported in Table 4 , showed that BSA strongly inhibited only the activities of AF/API and AF/ABDP.
Table 4. Influence of $30 \%$ bovine serum $(\simeq 12 \%$ BSA) on the MIC's of HQ-rifamycins against Staphylococcus aureus

\begin{tabular}{l|c|c|c}
\hline \multirow{2}{*}{ Type/AF } & \multicolumn{2}{|c|}{$\mathrm{MIC}(\mu \mathrm{g} / \mathrm{ml})$} & $\begin{array}{c}\mathrm{MIC} \\
(+\mathrm{BSA})\end{array}$ \\
\cline { 2 - 3 } & $0 \% \mathrm{BSA}$ & $12 \% \mathrm{BSA}$ & $\begin{array}{c}\text { MIC } \\
(-\mathrm{BSA})\end{array}$ \\
\hline $\mathrm{SV}$ & 0.012 & 0.012 & 1 \\
$\mathrm{AF} / \mathrm{AP}$ & 0.005 & 0.01 & 2 \\
$\mathrm{AF} / \mathrm{AMP}$ & 0.0025 & 0.005 & 2 \\
$\mathrm{AF} / \mathrm{AETP}$ & 0.005 & 0.005 & 1 \\
$\mathrm{AF} / \mathrm{ACPP}$ & 0.005 & 0.01 & 2 \\
$\mathrm{AF}^{\mathrm{A}} \mathrm{ABDP}{ }_{\mathrm{cis}}$ & 0.002 & 0.2 & 100 \\
$\mathrm{AF}^{\mathrm{A}} \mathrm{API}$ & 0.002 & 0.1 & 50 \\
\hline
\end{tabular}

Table 5. Free energies of formation of the complexes between $\mathrm{HQ}$ or $\mathrm{Q}$ rifamycins and BSA $37^{\circ} \mathrm{C}, \mathrm{pH} 7.4$.

\begin{tabular}{l|c|c|c}
\hline Type/AF & $\Delta G^{0}{ }_{(\mathrm{HQ})}$ & $\Delta G^{0}{ }_{(\mathrm{Q})}$ & $\begin{array}{c}\Delta G^{0}{ }_{(\mathrm{HQ})}- \\
\Delta G^{0}{ }_{(\mathrm{Q})}\end{array}$ \\
\hline SV & -6114 & -5316 & -799 \\
AP & -5964 & -5234 & -730 \\
AMP & -6018 & -5369 & -649 \\
AETP & -6103 & -5389 & -714 \\
ACPP & -6461 & -5293 & -1167 \\
ABDP & -7111 & -6978 & -133 \\
API & -6726 & -6097 & -629 \\
\hline
\end{tabular}




\section{Discussion}

All the rifamycins studied, in their reduced form (4-DSV, SV, AF/AP, AF/AMP, AF/AETP, AF/ ACPP, AF/ABDP, and AF/API) were found to interact with BSA and HSA with "combining affinityvalues" $\left(K_{\mathrm{a}} \times n\right)$ between $10^{3}$ and $10^{5}$ liters per mole. With the exception of AF/ABDP the binding strength to BSA was greater than to HSA. Lack of temperature-dependence suggests for all the $\mathrm{C}_{3}$ substituted rifamycins under investigation the formation of apolar or hydrophobic bonds which are essentially athermal entropy-driven interactions $(\Delta \mathrm{H}=0)$.

As to the interaction between SV and BSA, it is primarily entropically driven, but also shows temperature-dependence, the bonding mechanism involved appears to be of an electrostatic type in which the enthalpy change contributes to a minor extent to the free energy change ${ }^{14)}$. However, it is well known that thermodynamic parameters alone do not provide a diagnostic criterion for choosing between the types of forces involved in ligand binding by proteins. Indeed the molecular mechanism must be consistent with thermodynamics, but it is also clear that thermodynamic studies in themselves cannot select between alternative, consistent molecular explanations. Actually, in agreement with the hypothesis of an ionic interaction, the lowering of $\mathrm{pH}$, which causes a decrease of the net charge on the albumin molecule without affecting the dissociation of the $\mathrm{C}_{1}-\mathrm{C}_{8}$ dihydroxyl group, leads to an increased binding strength of rifamycin SV. On the contrary, for the other $\mathrm{C}_{3}$-substituted rifamycins, lowering the $\mathrm{pH}$ causes a weakening of the binding strength. This last finding is consistent with two possible mechanisms: (1) uncovering of new binding sites on the albumin molecule, which may result from a reversible swelling induced by the strong electrostatic repulsions that develop in a protein molecule with an increase in negative charge ${ }^{15 \sim 18)}$, (2) an increased dissociation of the cationic nitrogen of the piperazine moiety, causing in itself or through the formation of an internal salt a noncompetitive inhibition of the ionic site(s) of the albumin molecules. In order to avoid a misleading interpretation of the data on the $\mathrm{pH}$-dependence, we want to emphasize that the results obtained with the $\mathrm{C}_{3}$-substituted rifamycins, according to the last hypothesis, are consistent also with ionic interactions.

Additional information about the binding mechanism was obtained from the data showing that the strength of the bond of the hydroquinone form was greater than that of the quinone form (Table 1), and those showing that of the two hydroquinonic hydroxyl groups the one in position 1 is the only one involved, directly or indirectly, either favouring or inhibiting the formation of the rifamycin-albumin complex (see 4-DSV). Apropos of this effect, it is to be emphasized that in the quinonic form the keto group at $\mathrm{C}_{1}$ forms a hydrogen bridge with the phenolic hydroxyl at $\mathrm{C}_{8}$, thus diminishing its acid strength. Effectively, the free-energies of formation of the rifamycin-BSA complexes for the quinonic forms of $\mathrm{SV}, \mathrm{AF} / \mathrm{AP}, \mathrm{AF} / \mathrm{AMP}, \mathrm{AF} / \mathrm{AETP}$, and AF/ACPP, are practically identical, ranging between 5,234 and $5,389 \mathrm{cal} . / \mathrm{mole}$, while those of Q AF/API (6,097 cal./mole) and Q AF/ABDP (6,978 cal./mole) are higher. These data, together with the $\left[\Delta \mathrm{G}_{(\mathrm{HQ})}^{0}-\Delta G_{(\mathrm{Q})}^{0}\right]$-differences, are reported in Table 5, and appear to differentiate the binding mechanism of AF/API and AF/ABDP from that of the other rifamycins.

Although it is not clear whether the apparently different nature of the binding of AF/API and AF/ ABDP to BSA bears any relation to the fact that these two rifamycins are the only ones whose antibacterial activity is strongly inhibited by the presence of albumin, undoubtedly this remains an attractive hypothesis. To summarize: a) all rifamycins may probably interact with albumin by a low affinity nonspecific binding, which involves the basic molecular structure either in the reduced or oxidized form (e.g. rifamycin $\mathrm{S})$.

b) Rifamycin $\mathrm{SV}$ forms an ionic bond through the $\mathrm{C}_{1}-\mathrm{C}_{8}$ dihydroxy acid function. The same bonding seems to be retained also by rifamycins AF/AP, AF/AMP, AF/AETP, AF/ACPP, AF/ABDP, and AF/API in their hydroquinone forms, even taking into account a probable inhibiting action of the piperazine cation*.

c) Very probably, rifamycins $\mathrm{AF} / \mathrm{ABDP}$ and $\mathrm{AF} / \mathrm{API}$, either as hydroquinones or quinones,

* The stronger ionic bonding of AF/ACPP, probably rises from the structural features, the lower dissociation of the anionic function, and the steric masking by the cyclopentyl ring on the basic nitrogen of the piperazine moiety. 
through the piperazine or piperidine lipophilic side chains, undergo also hydrophobic interactions.

d) The number of binding sites to BSA should be nearly 1 for SV, AF/AP, AF/AMP, AF/AETP and $\mathrm{AF} / \mathrm{ACPP},>1$ for $\mathrm{AF} / \mathrm{API}$ and $\mathrm{AF} / \mathrm{ABDP}^{19)}$.

e) The binding mechanisms do not have to be correlated in any way with the lipophilic indices of the different rifamycins even though they seem to be on casual scrutiny.

Although the factors which completely characterize formation of these complexes are probably diverse and more complicated than indicated, in any event, the authors suggest that the mechanism deduced, even though hypothetical, may prove to be of use in a research program for new semi-synthetic rifamycins substituted in position $\mathrm{C}_{3}$, in so far as studies in progress have demonstrated the influence of binding to serum albumin on the pharmacological and pharmacokinetic behaviour of these antibiotics.

Acknowledgement

The authors are indebted to Prof. G. G. Gallo and to Prof. G. LanCINI for useful suggestions and criticism.

\section{References}

1) Meyer, M. C. \& D. E. Guttman: The binding of drugs by plasma proteins. J. Pharm. Sci. 57: 895 915, 1968

2) KeEN, P.: Effect of binding to plasma proteins on the distribution, activity and elimination of drugs. in Concepts in Biochemical Pharmacology. I. B. B. Brodie \& J. R. Gillette Eds. 28(1): 213 233. Springer Verlag N.Y. 1971

3) Anton, A. H.: The relation between the binding of sulfonamides to albumin and their antibacterial efficacy. J. Pharmacol. Exp. Ther. 129: 282 290, 1960

4) Kunin, C. M.: Effect of serum binding on the distribution of penicillins in the rabbit. J. Lab. Clin. Med. 65: 406 415, 1965

5) Sensi, P.; M. MagGi, S. Furesz \& G. Maffil: Chemical modifications and biological properties of rifamycins. Antimicr. Agents \& Chemoth. -1966: 699 714, 1967

6) Assandri, A. \& G. Semenza: Protein binding of rifampicin to bovine serum albumin as measured by gel filtration. J. Chromatogr. 135: 25 35, 1977

7) Arioli, V.; M. Berti \& L. G. Silvestri: Gardimycin, a new antibiotic from Actinoplanes. III. Biological properties. J. Antibiotics 29: 511 515, 1976

8) Pelizza, G.; G. C. Lancini, G. C. Allievi \& G. G. Gallo: The influence of lipophilicity on the antibacterial activity of rifamycins. Il Farmaco Ed. Sci. 28: 293 315, 1973

9) Boyce, C. B. C. \& B. V. Milborrow: A single assessement of partition data for correlating structure and biological activity using thin-layer chromatography. Nature 208: 537 539, 1965

10) Gallo, G. G.; C. R. Pasqualucci \& P. Radaelli: Analisi spettrofotometrica della rifamicina SV. Il Farmaco Ed. Pra. 18: 78 84, 1963

11) Pasqualucci, C. R.; A. Vigevani, P. Radaelli \& M. Maggi: Analisi spettrofotometrica della rifamicina. Il Farmaco Ed. Pra. 24: 46 52, 1969

12) RADAeLli, P.: Ionization constants of the 3-formyl rifamycin SV hydrazones. Unpublished results.

13) Albert, A \& E. P. Serjeant: Ionization constants of acids and bases. p. 117, London, Methuen and Co. Ltd. 1962

14) Klotz I. M.: Physicochemical of drug-protein interaction: a general perspective. Ann. N.Y. Ac. Sci. 226: $18 \sim 351973$

15) Klotz, I. M. \& J. Ayers: Protein interaction with organic molecules. Discuss. Faraday Soc. 13: 189 196,1953

16) Leonard, J.; K. K. ViJai \& J. F. Foster: A structural transformation in bovine and human plasma albumins in alkaline solution as revealed by rotatory dispersion studies. J. Biol. Chem. 238: 1984 1988, 1963

17) Klotz, I. M.; R. K. Burkhard \& J. M. Urguhart: Structural specificities in the interaction of some organic ions with serum albumin. J. Am. Chem. Soc. 74: 202 208, 1952

18) O'ReIlly, R. A. \& P. E. Kowitz: Warfarin albumin binding: physicochemical and metabolic characteristics. Fed. Proc. 26: 615, 1967

19) AsSANDRI, A. \& L. Moro: Protein binding of a series of rifamycins to bovine serum albumin as measured by two-phase partition techniques. J. Cromatogr. 135: 37 48, 1977 


\section{NOTES}

\section{BIOSYNTHESIS OF AURODOX} (ANTIBIOTIC X-5108).

\section{INCORPORATION OF ${ }^{14} \mathrm{C}$-LABELLED PRECURSORS INTO AURODOX ${ }^{1,2)}$}

\section{Chao-min Liu, Hubert Maehr, Michael Leach, Mark Liu and Philip A. Miller \\ Chemical Research Department Hoffmann-La Roche Inc. \\ Nutley, New Jersey 07110, U.S.A. \\ (Received for publication March 2, 1977)}

Streptomyces goldiniensis produces aurodox ${ }^{31}$ (1) and small amounts of its N-demethyl homolog mocimycin (2) $)^{4)}$ which is probably identical ${ }^{51}$ with kirromycin ${ }^{6,71}$. These antibiotics and a recently discovered disaccharide derivative of aurodox $(3)^{8)}$ are primarily active against Grampositive bacteria and enhance the growth of farm animals. The chemical structures, including stereochemistry, have been elucidated for aurodox and mocimycin ${ }^{5.91}$. Since aurodox is a member of a new class of antibiotics, biosynthetic studies of aurodox were of particular interest. In this report we describe the incorporation of ${ }^{14} \mathrm{C}$ labelled precursors into aurodox.

The carbon skeleton of aurodox suggests that the antibiotic is in part derived from coupling of acetate units via the polyketide biosynthetic route $^{101}$. The $\mathrm{C}$-methyl groups could arise through transmethylations from suitable $\mathrm{C}_{1}$ donors $^{11)}$ or by the insertion of propionate ${ }^{121}$ or isoprenoid units. The C-ethyl group could be generated by the incorporation of a butyrate unit into the polyketide chain ${ }^{13)}$, whereas the pyridone ring of aurodox could be derived via the nicotinic acid pathway ${ }^{14 l}$ or, alternatively, from cadaverine. These possibilities were examined experimentally by measuring the incorporation of various ${ }^{14} \mathrm{C}$-labelled precursors into aurodox (Table 1).

Radioactively labelled substrates at $10 \sim 100$ $\mu \mathrm{Ci}$ per $100 \mathrm{ml}$ broth were individually added to fermentation cultures of $S$. goldiniensis 2 days after inoculation. After a further 5-day incubation period, aurodox was isolated according to procedures previously described ${ }^{3)}$.

According to the data in Table 1 the labels of methionine, glycine, acetate, propionate, butyrate, and $\beta$-hydroxybutyrate were incorporated into aurodox. The pattern of these incorporations (Table 2) was determined by measuring the radioactivity in fragments of aurodox derived by the degradation scheme ${ }^{15,16)}$ shown in Fig. 1.

The distribution of radioactivity in acetatederived aurodox reveals little about the assembly of the polyketide chain. In contrast, the incorporation patterns of propionate and butyrate clearly show that an intact unit of each of these precursors is incorporated into aurodox. Localization of all three propionate carbons in fragment 8 suggests that propionate is incorporated into $\mathrm{C}-41$ and $\mathrm{C}-8$ as well as either C-7 or C-9. Butyrate labelling of goldinono-1,4-lactone-3,7hemiacetal (5) may be due to incorporation into the C-ethyl carbons 45 and 46, and the two adjacent carbons 27 and 28 . $\beta$-Hydroxybutyrate, a known precursor of butyrate, was also incorporated primarily into 5. Perhaps the most interesting result is the extent of incorporation of methionine-methyl- ${ }^{14} \mathrm{C}(9.7 \%)$ and the locali-

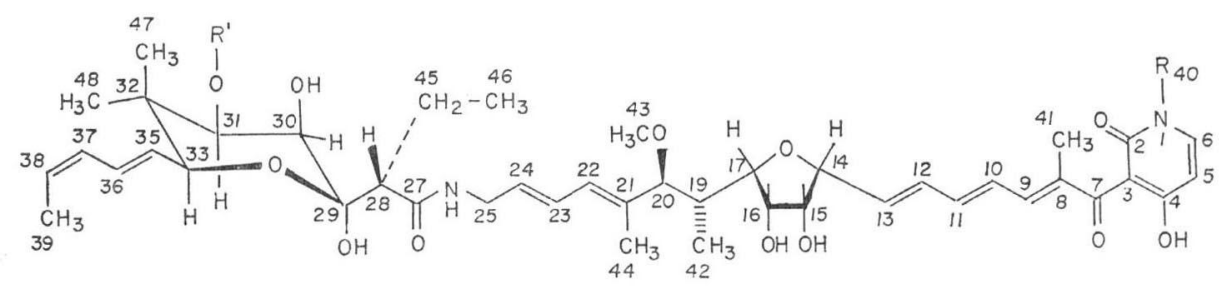

I Aurodox $(X-5108) \quad R=\mathrm{CH}_{3}: R^{\prime}=\mathrm{H}$
2 Mocimycin (Kirromycin) $R=\mathrm{R}^{\prime}=\mathrm{H}$
3 Efrotomycin $\mathrm{R}=\mathrm{CH}_{3}: \mathrm{R}^{\prime}=$ Disaccharide $\left(\mathrm{C}_{15} \mathrm{H}_{27} \mathrm{O}_{8}\right)$ 
zation of radioactivity in $5(33 \%)$. These observations suggest that the geminal $\mathrm{C}$-methyl groups at C-32 are derived from methioninemethyl; the lack of any incorporation of mevalonate- $2-{ }^{14} \mathrm{C}$ and of incorporation of propionate into $\mathbf{5}$ are consistent with this proposal. The incorporation pattern of methionine methyl- ${ }^{14} \mathrm{C}$ also suggests that the $\mathrm{N}$-methyl (C-40), O-methyl (C-43), and two of the three C-methyls, (C-42 and

Table 1. Incorporation of ${ }^{14} \mathrm{C}$-labelled substrates into aurodox

\begin{tabular}{|c|c|}
\hline Substrate (sodium salts) & $\begin{array}{c}\text { Percentage } \\
\text { incorporation }\end{array}$ \\
\hline Acetate- $1-{ }^{14} \mathrm{C}$ & 2.6 \\
\hline Acetate $-2-{ }^{14} \mathrm{C}$ & 2.1 \\
\hline Propionate- $1-{ }^{14} \mathrm{C}$ & 2.2 \\
\hline Propionate- $2-{ }^{14} \mathrm{C}$ & 1.6 \\
\hline Propionate- $3-{ }^{14} \mathrm{C}$ & 0.9 \\
\hline Butyrate-1-14 C & 2.2 \\
\hline Butyrate-2-14 $\mathrm{C}$ & 2.6 \\
\hline Butyrate- $3,4-{ }^{14} \mathrm{C}$ & 2.2 \\
\hline$\beta$-Hydroxybutyrate-3- ${ }^{14} \mathrm{C}$ & 2.5 \\
\hline Methionine-methy]- ${ }^{14} \mathrm{C}$ & 9.7 \\
\hline Glycine-1-14 $\mathrm{C}$ & 0.8 \\
\hline Glycine-2- ${ }^{14} \mathrm{C}$ & 2.9 \\
\hline Cadaverine- $1,5-{ }^{14} \mathrm{C}$ & 0.6 \\
\hline Mevalonate-2- ${ }^{14} \mathrm{C}$ & 0 \\
\hline Formate- ${ }^{14} \mathrm{C}$ & 0 \\
\hline Nicotinic acid-7- ${ }^{14} \mathrm{C}$ & 0 \\
\hline Quinolinic acid-6- ${ }^{14} \mathrm{C}$ & 0 \\
\hline
\end{tabular}

C-44) are also derived from methionine. Glycine- $2-{ }^{14} \mathrm{C}$ incorporation follows the same patterns as methionine-methyl- ${ }^{14} \mathrm{C}$, presumably because the methylene carbon of glycine serves as a $\mathrm{C}_{1}$-donor.

The origin of the pyridone moiety of aurodox remains to be determined. The nicotinic acid pathway is apparently not involved since nicotinic acid-7- ${ }^{14} \mathrm{C}$ and quinolinic acid- $6-{ }^{14} \mathrm{C}$ were not incorporated. The possibility that cadaverine plays a role in the synthesis of the pyridone group was ruled out by the observation that the total radioactivity in the goldinamine part isolated as $\mathbf{6}$, was lower than that contained in the goldinonic acid portion, isolated as $\mathbf{5}$.

From these results, the following conclusions can be drawn: (1) Only one propionate unit and one butyrate unit are utilized by $S$. goldiniensis in the assembly of the antibiotic carbon skeleton; (2) six methyl groups are most likely derived via transfer of one-carbon units; (3) the pyridone group is not derived from nicotinic acid or cadaverine. Spectroscopic studies with ${ }^{13} \mathrm{C}$ enriched aurodox derived from ${ }^{13} \mathrm{C}$-labelled precursors should permit more specific determination of the biosynthetic origin and are now in progress.

\section{References and notes}

1) A preliminary account of this study was presented at the Annual Meeting of the American Society for Microbiology, 1974. (Abstr. Ann. Meeting American Society for Microbiology,

Table 2. Distribution of label radioactivity in aurodox derived from various ${ }^{14} \mathrm{C}$-labelled precursors

\begin{tabular}{|c|c|c|c|c|}
\hline \multirow{2}{*}{ Labelled precursor } & \multicolumn{4}{|c|}{ Molar radioactivity, percent of aurodox } \\
\hline & 5 & 6 & 7 & 8 \\
\hline Acetate- $1-{ }^{14} \mathrm{C}$ & 49.6 & 50.5 & 38.9 & 11.5 \\
\hline Acetate- $2-{ }^{14} \mathrm{C}$ & 42.6 & 57.4 & 41.4 & 16.0 \\
\hline Propionate- $1-{ }^{14} \mathrm{C}$ & 1.0 & 98.7 & 1.2 & 89.1 \\
\hline Propionate- $2-{ }^{14} \mathrm{C}$ & 5.1 & 99.2 & 4.5 & 87.6 \\
\hline Propionate- $3-{ }^{14} \mathrm{C}$ & 5.7 & 92.7 & 5.4 & 88.4 \\
\hline Butyrate- $1-{ }^{14} \mathrm{C}$ & 73.8 & 29.5 & 3.5 & 22.5 \\
\hline Butyrate- $2-{ }^{14} \mathrm{C}$ & 73.2 & 37.4 & 12.1 & 23.3 \\
\hline Butyrate- $3,4-{ }^{14} \mathrm{C}$ & 62.7 & 44.1 & 8.5 & 33.8 \\
\hline$\beta$-Hydroxybutyrate- $3-{ }^{14} \mathrm{C}$ & 79.1 & 20.9 & ND* & ND \\
\hline Methionine-methyl- ${ }^{14} \mathrm{C}$ & 33.8 & 67.3 & 41.4 & 26.0 \\
\hline Glycine-2- ${ }^{14} \mathrm{C}$ & 32.4 & 67.2 & 52.8 & 12.0 \\
\hline Cadaverine- $1,5-{ }^{14} \mathrm{C}$ & 63.0 & 37.0 & ND & ND \\
\hline
\end{tabular}

* $\mathrm{ND}=$ not determined 
Fig. 1. Degradation of aurodox bromobenzyl ether<smiles>[R]CCc1ccc(Br)cc1</smiles>

p. 19, 1974).

2) Aurodox is the nonproprietary designation for antibiotic X-5108 and has been selected by the U.S. Adopted Names Council. The previously proposed name "goldinodox" has been withdrawn.

3) Berger, J.; H. H. Lehr, S. Teitel, H. Maehr \& E. GrunberG: A new antibiotic X-5108 of Streptomyces origin. 1. Production, isolation and properties. J. Antibiotics 26: 15 22, 1973

4) Vos, C. \& P. E. J. Verwiel: The total structure of the novel antibiotics mocimycin (MYC 8003). Tetrahedron Lett. 1973: 5173 5176, 1973

5) Maehr, H.; M. Leach, L. YarmchuK \& A. STEMPEL: Antibiotic X-5108. V. Structures of antibiotic X-5108 and mocimycin. J. Amer. Chem. Soc. 95: 8449 8450, 1973

6) Wolf, H. \& H. ZäHNER: Stoffwechselprodukte von Mikroorganismen. 99 Mitteil. Kirromycin. Arch. Mikrobiol. 83: 147 154, 1972

7) LiU, C-M.: Unpublished observation.

8) Wax, R.; W. Maiese, R. Weston \& J. Birnbaum: Efrotomycin, a new antibiotic from Streptomyces lactamdurans. J. Antibiotics 29: 670 673, 1976

9) Maehr, H.; M. Leach, J. F. Blount \& A. Stempel: Antibiotic X-5108. VIII. Absolute stereochemistry of antibiotic X-5108 and mocimycin. J. Amer. Chem. Soc. 96: 4034 4035, 1974

10) Birch, A. J.: Biosynthesis of polyketides and related compounds. Science 156: 202 206, 1967

11) Birch, A. J.; R. J. English, R. A. MasseyWestrop, M. Slaytor \& H. Smith: Studies on relation to biosynthesis. XIV. The origin of the nuclear methyl groups in mycophenolic acid. J. Chem. Soc. 1958: 365 368, 1958

12) Kaneda, T.; J. C. Butte, S. B. Taubman \& J.W. Corcoran: Actinomycete antibiotics. III. The biogenesis of erythronolide, the $\mathrm{C}_{21}$ branched chain lactone in erythromycin. J. Biol. Chem. 237: 322 328, 1962

13) Westley, J. W.; R. H. Evans, Jr., G. Harvey, R. G. Pitcher, D. L. Pruess, A. Stempel \& J. Berger: Biosynthesis of lasalocid. 1. Incorporation of ${ }^{13} \mathrm{C}$ and ${ }^{14} \mathrm{C}$ labelled substrates 
into lasalocid A. J. Antibiotics 27: 288 297, 1974

14) Fu, P.; J. Kobus \& T. Robinson: The multiplicity of pyridinium oxidases in Ricinus communis. Phytochemistry 11: 105 112, 1972

15) Maehr, H.; J. F. Blount, R. H. Evans, Jr., M. Leach, J. W. Westley, T. H. Williams, A. Stempel \& G. Büchi: Antibiotic X-5108.
II. Structure of goldinono-1,4-lactone-3,7hemiketal, a degradation product of the antibiotic. Helv. Chem. Acta 55: $3051 \sim 3054$, 1972

16) Maehr, H.; M. Leach, T. H. Williams, W. Benz, J. F. Blount \& A. Stempel: Antibiotic $\mathrm{X}-5108$. IV. Structure of goldinamine. J. Amer. Chem. Soc. 95: 8448 8449, 1973 